\title{
Sound Radiation Characteristics of a Rectangular Duct with Flexible Walls
}

\author{
Praveena Raviprolu, Nagaraja Jade, and Venkatesham Balide \\ Department of Mechanical \& Aerospace Engineering, Indian Institute of Technology Hyderabad, Kandi, Telangana 502285, India
}

Correspondence should be addressed to Venkatesham Balide; venkatesham@iith.ac.in

Received 30 July 2016; Revised 10 October 2016; Accepted 19 October 2016

Academic Editor: Marc Thomas

Copyright (C) 2016 Praveena Raviprolu et al. This is an open access article distributed under the Creative Commons Attribution License, which permits unrestricted use, distribution, and reproduction in any medium, provided the original work is properly cited.

\begin{abstract}
Acoustic breakout noise is predominant in flexible rectangular ducts. The study of the sound radiated from the thin flexible rectangular duct walls helps in understanding breakout noise. The current paper describes an analytical model, to predict the sound radiation characteristics like total radiated sound power level, modal radiation efficiency, and directivity of the radiated sound from the duct walls. The analytical model is developed based on an equivalent plate model of the rectangular duct. This model has considered the coupled and uncoupled behaviour of both acoustic and structural subsystems. The proposed analytical model results are validated using finite element method (FEM) and boundary element method (BEM). Duct acoustic and structural modes are analysed to understand the sound radiation behaviour of a duct and its equivalence with monopole and dipole sources. The most efficient radiating modes are identified by vibration displacement of the duct walls and for these the radiation efficiencies have been calculated. The calculated modal radiation efficiencies of a duct compared to a simple rectangular plate indicate similar radiation characteristics.
\end{abstract}

\section{Introduction}

The most commonly used duct cross sections are rectangular, flat oval, and circular in heating, ventilation, and air-conditioning (HVAC) applications. Ducts transport the conditioned air from an air-handling unit (AHU) to an occupied space. Similarly, the sound produced from an AHU propagates to the receiver (a room or space) in longitudinal and transverse direction of the duct. The radiated noise from the duct walls traveling in the transverse direction is called "breakout noise." Breakout noise is one of the common paths of sound transmission in HVAC thin wall ducts. Cummings [1] discussed the role of various duct cross section geometries on the breakout and break-in noise. Further, Cummings provided research review progress for the past two decades on "duct breakout noise."

Of all the geometries, rectangular ducts had maximum breakout noise at lower frequencies, which means minimum wall transmission loss. Breakout noise causes the structuralacoustical coupling between the flexible duct wall structure and the acoustic domain inside the duct volume. Airborne and structure-borne sounds contribute to duct breakout noise, which is more dominant at low frequencies [1]. The hydrodynamic force and the acoustic pressure waves excite the duct wall and cause structure-born noise. These forces and pressure waves are associated with the flow and sound propagation through the duct, respectively. The excitation due to hydrodynamic force generates lower frequency vibration, which could be a focus for fatigue analysis.

An acoustic wave excites the duct walls strongly and induces vibrations. The produced vibrations of the structure will induce acoustic pressure inside the duct. This phenomenon continues under coupling and it is efficient at the strongly coupled modes. Coupling depends on the acoustic, structural natural frequency and spatial distribution of mode shapes. Transfer factor identifies the strongly coupled structural and acoustical modes [2]. Vibration displacement of the flexible structure due to acoustic excitation produces sound radiation outside the duct volume. The radiated sound power depends on vibration velocity, surface area, and radiation efficiency [3]. In the present paper, mean flow effects are not considered because of lower Mach numbers in the HVAC ducts.

Analytical methods are available in the literature for calculating the sound radiation from different ducts, such as 
a finite-length line source, equivalent finite-length cylindrical radiator, equivalent plate model, and finite and boundary element methods [1-5]. Cummings estimated the breakout noise from a rectangular duct using line source model and equivalent cylinder model. Astley and Cummings discussed a finite element scheme and an experimental setup to study the acoustic transmission through walls of a rectangular duct. Venkatesham et al. developed an analytical solution for prediction of breakout noise from the rectangular duct [4] and a plenum with four compliant walls [5] based on an equivalent plate model for sound radiation. In this model, the acoustic pressure and the vibration velocity vectors were expressed in terms of uncoupled acoustical and structural subsystems. The radiated sound power was expressed in terms of radiation impedance matrix and average velocity vector. Quadruple integrals are involved in the radiation impedance matrix. Venkatesham et al. [5] discussed a procedure for solving quadruple integrals based on the coordinate transformation. The same method is extended in the current manuscript to determine rectangular duct sound radiation characteristics.

Modal radiation efficiency calculation helps in finding efficient sound radiation modes in the total sound power radiated from a duct. Wallace [6] discussed an analytical formula for calculating radiation efficiencies at low frequencies from a baffled rectangular plate. Ran Lin and Pan [7] studied the vibration and sound radiation characteristics of box structures. It provides a basis for understanding the vibration energy flows between the panels of the box, grouping of various modes, radiation efficiencies, and the various kinds of sound sources.

In this paper, the uncoupled structural modes of the rectangular duct and acoustical cavity modes are calculated by the analytical method and validated with the numerical results. These rectangular duct modes are classified into four different groups and are similar to box structures as discussed in [7]. In these four groups, the most efficient radiating modes are estimated based on the symmetries between the panel pairs and the net volume displacements in a particular mode. The modal radiation efficiencies of different groups of a rectangular duct are estimated and compared analytically and numerically. These modal radiation efficiencies of the rectangular duct of the four groups are compared to that of simple rectangular plate. This comparison shows a similarity between duct sound radiation behaviours in terms of plate modes. As a part of the study, the total sound power radiated from the duct walls is estimated by using finite element method (FEM) and boundary element method (BEM). The sound radiation behaviour of a duct is also studied to understand its equivalence with monopole and dipole sources. The total radiation efficiencies of coupled acoustic and structural modes are calculated. These results are used for validation of the proposed analytical model.

\section{Theoretical Formulation}

The outline of the formulation of an analytical model of sound radiation from the rectangular duct is shown in Figure 1. The objective here is to calculate the total sound power radiation and radiation efficiency from the flexible duct walls. Assump-

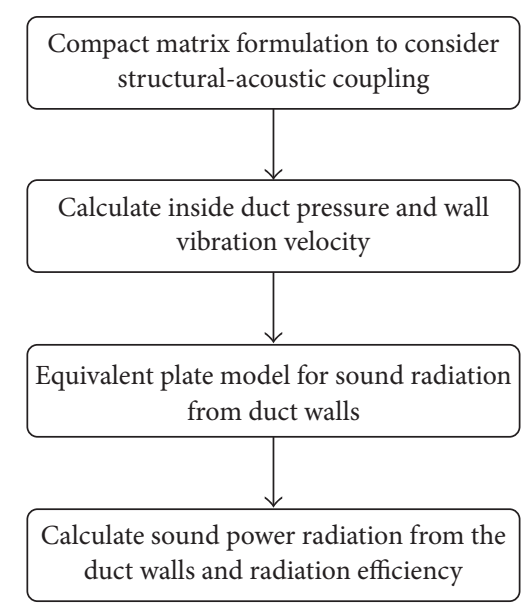

FIGURE 1: Flow chart of theoretical formulation methodology.

tions made in this model are (i) strong coupling amongst inside duct volume and flexible duct wall area; (ii) weak coupling between flexible wall area and outside environment; (iii) that coupled behaviour can be expressed in terms of a finite number of uncoupled acoustic and structural modes.

The proposed model has two stages. In the first stage, inside duct pressure and wall vibration velocity, due to an acoustic excitation, are calculated by considering the structural-acoustical coupling and impedance-mobility approach. In this approach, the coupled response between the structural and acoustical domains is represented in the form of uncoupled acoustic and structural subsystems natural frequencies and mode shapes. In the second stage, an equivalent plate model with duct wall vibrations as boundary condition is developed to predict the characteristics of sound radiation. Further details are discussed in Section 2.2.

2.1. Pressure Field inside the Duct and Wall Vibration Velocity. Pressure field inside the duct in terms of uncoupled acoustic mode shapes is given as

$$
p(\mathbf{x}, \omega)=\sum_{n} \psi_{n}(\mathbf{x}) a_{n}(\omega)=\psi^{T} \mathbf{a} .
$$

The compliant duct wall vibration velocity is given as

$$
w(\mathbf{z}, \omega)=\sum_{m} \Phi_{m}(\mathbf{z}) b_{m}(\omega)=\boldsymbol{\phi}^{T} \mathbf{b}
$$

where $\psi_{n}(\mathbf{x})$ is an uncoupled acoustic mode shape function of the duct, $a_{n}(\omega)$ is the complex amplitude of the $n$th acoustic pressure mode, $\Phi_{m}(\mathbf{z})$ is an uncoupled vibration mode shape function of the duct, and $b_{m}(\omega)$ is the complex amplitude of the $m$ th vibration velocity mode.

Complex amplitude of the $n$th acoustic mode under structural and acoustic excitation is given as [8]

$$
\begin{aligned}
& a_{n}(\omega)=\frac{\rho_{0} c_{0}^{2}}{V} A_{n}(\omega) \\
& \quad\left(\int_{V} \psi_{n}(\mathbf{x}) s(\mathbf{x}, \omega) d V+\int_{S_{f}} \psi_{n}(\mathbf{y}) w(\mathbf{y}, \omega) d S\right),
\end{aligned}
$$




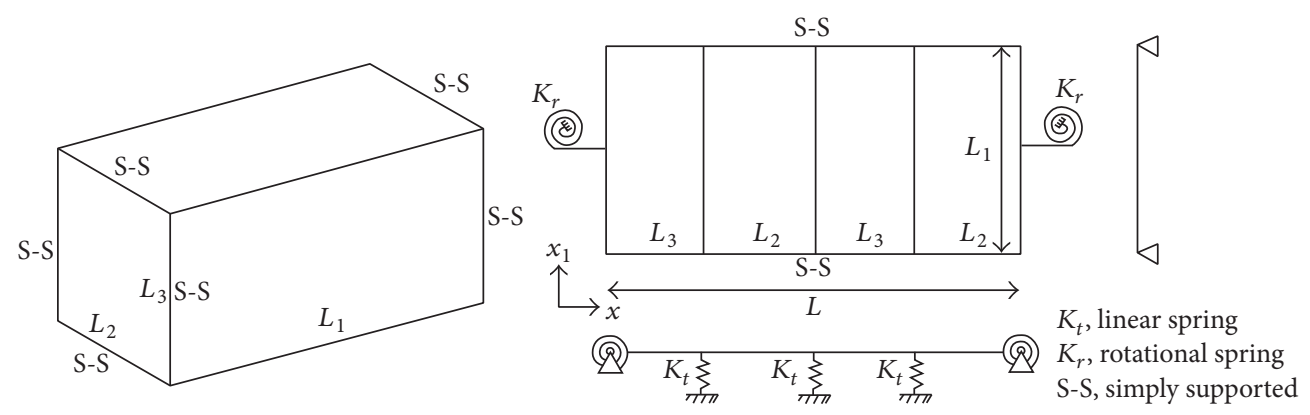

FIGURE 2: Equivalent plate representation of a rectangular duct with simply supported boundary condition.

where $\rho_{0}$ and $c_{0}$ denote the density and speed of sound in air, respectively. Function $s(\mathbf{x}, \omega)$ denotes the acoustic density function (volume velocity per unit volume) in the duct volume $V$ and $w(\mathbf{z}, \omega)$ denotes normal velocity of a surrounding flexible structure for surface area $S_{f}$.

The complex vibration velocity amplitude of the $m$ th mode can be expressed as [8]

$$
\begin{aligned}
& b_{m}(\omega)=\frac{1}{\rho_{s} h S_{f}} B_{m}(\omega) \\
& \quad \cdot\left(\int_{S_{f}} \Phi_{m}(\mathbf{z}) f(\mathbf{z}, \omega) d S-\int_{S_{f}} \Phi_{m}(\mathbf{z}) p(\mathbf{z}, \omega) d S\right),
\end{aligned}
$$

where $\rho_{s}$ and $h$ denote density of the material and thickness of the duct wall, respectively. $f(\mathbf{z}, \omega)$ is the force distribution on the surface of the duct wall. $p(\mathbf{z}, \omega)$ is the inside acoustic pressure distribution on the surface of the duct wall.

Uncoupled acoustical mode shapes and natural frequencies of a rectangular duct are calculated by using the formula given in [8]. Similarly, an equivalent plate model is used to calculate the uncoupled structural mode shapes and the natural frequency of rectangular duct.

Modal acoustic pressure vector a given in (1) and (3) has been expressed in terms of impedance and mobility as

$$
\mathbf{a}=\mathbf{Z}_{\mathbf{a}}\left(\mathbf{q}+\mathbf{q}_{\mathbf{s}}\right) .
$$

$\mathbf{Z}_{\mathbf{a}}=\mathbf{A} \rho_{0} c_{0}^{2} / V$ is the uncoupled acoustic modal impedance matrix and $\mathbf{q}$ is the modal source strength vector and $\mathbf{q}_{\mathbf{s}}=$ $\mathbf{C b}$, where $\mathbf{C}$ is the matrix representing coupling coefficient $C_{n, m}$ between $n$th acoustic mode and $m$ th structural mode. Coupling represents the spatial distribution of an acoustic mode on the flexible surface.

Modal structural vibration velocity vector $\mathbf{b}$ given in (2) and (4) can be expressed in matrix form as

$$
\mathbf{b}=\mathbf{Y}_{\mathbf{s}}\left(\mathbf{g}-\mathbf{g}_{\mathbf{a}}\right)
$$

$\mathbf{Y}_{\mathbf{s}}=\mathbf{B} / \rho_{s} h S_{f}$ represents uncoupled structural mobility matrix and $\mathbf{g}$ is the generalized modal force vector and $\mathbf{g}_{\mathbf{a}}=$ $\mathbf{C}^{\mathrm{T}} \mathbf{a}$.
Using (5) and (6), the complex amplitude of acoustic and structural modes is given as

$$
\begin{aligned}
& \mathbf{a}=\left(\mathbf{I}+\mathbf{Z}_{\mathbf{a}} \mathbf{C Y}_{\mathbf{s}} \mathbf{C}^{\mathrm{T}}\right)^{-1} \mathbf{Z}_{\mathbf{a}}\left(\mathbf{q}+\mathbf{C Y}_{\mathbf{s}} \mathbf{g}\right), \\
& \mathbf{b}=\left(\mathbf{I}+\mathbf{Y}_{\mathbf{s}} \mathbf{C}^{\mathrm{T}} \mathbf{Z}_{\mathbf{a}} \mathbf{C}\right)^{-1} \mathbf{Y}_{\mathbf{s}}\left(\mathbf{g}-\mathbf{C}^{\mathrm{T}} \mathbf{Z}_{\mathbf{a}} \mathbf{q}\right) .
\end{aligned}
$$

When $\left(\mathbf{I}+\mathbf{Z}_{\mathbf{a}} \mathbf{C Y}_{\mathrm{s}} \mathbf{C}^{\mathbf{T}}\right)^{-\mathbf{1}} \sim \mathbf{I}$ or $\left(\mathbf{I}+\mathbf{Y}_{\mathrm{s}} \mathbf{C}^{\mathbf{T}} \mathbf{Z}_{\mathrm{a}} \mathbf{C}\right)^{-\mathbf{1}} \sim \mathbf{I}$ or coupling matrix is zero matrix then (7) and (8) calculate uncoupled system responses. Selection of the strongly coupled acoustic and structural modes is done based on a transfer factor [2] which is given as

$$
T_{n, m}=\left(1+\frac{\left(\omega_{n}^{2}-\omega_{m}^{2}\right) \rho_{s} h S_{f} V}{4 \rho_{0} c_{0}^{2} C_{n, m}^{2}}\right)^{-1} .
$$

$T_{n, m}$ can be interpreted as a transfer factor for $n$th acoustic mode coupled to $m$ th structural mode.

2.2. Equivalent Plate Representation. In this method, an unfolded equivalent plate representation is used to model the rectangular duct. Figure 2 shows the rectangular duct and its equivalent plate representation of dimensions $L \times L_{1}$, respectively, where $L$ is the duct perimeter and $L_{1}$ is the duct length. The folded joint shown in Figure 2 is modelled as a rotational spring $\left(K_{r}\right)$ and creases of two adjacent plate panels are modelled as linear springs $\left(K_{t}\right)$. A simply supported (S-S) boundary condition is applied to equivalent plate boundaries along the axial direction (i.e., along the $x$-axis at $x_{1}=0$ and $L_{1}$ ). Rayleigh-Ritz method is used to calculate the duct's uncoupled structural mode shapes and natural frequencies. The description of Rayleigh-Ritz model of an equivalent plate to calculate the uncoupled natural frequency of various axial boundary conditions is given in [9].

2.3. Calculation of Sound Power and Radiation Efficiency. The sound power radiated from the duct wall is expressed in terms of modal amplitudes of vibration velocity (b) and radiation impedance matrix $[\mathbf{Z}]$. It is given as follows:

$$
W_{\text {rad }}=\frac{1}{2} \mathbf{b}^{\mathbf{H}} \operatorname{Re}[\mathbf{Z}] \mathbf{b},
$$


where the superscript $\mathbf{H}$ is Hermitian transpose and $\mathrm{Re}$ indicate the real value.
The radiation impedance can be expressed in terms of Rayleigh integral as

$$
\begin{aligned}
& \operatorname{Re}\left[Z_{m_{1} m_{2} m_{1}^{\prime} m_{2}^{\prime}}\right]=\frac{k}{2 \pi} \\
& \quad \cdot \int_{0}^{L} \int_{0}^{L_{1}} \int_{0}^{L} \int_{0}^{L_{1}} \sum_{m_{1}} \sum_{m_{2}} A_{m_{1} m_{2}} \sin \frac{m_{1} \pi x}{L} \sin \frac{m_{2} \pi x_{1}}{L_{t}} * \cdots \sum_{m_{1}^{\prime} m_{2}^{\prime}} A_{m_{1}^{\prime} m_{2}^{\prime}} \sin \frac{m_{1}^{\prime} \pi x^{\prime}}{L} \sin \frac{m_{2}^{\prime} \pi x_{1}^{\prime}}{L_{1}} \frac{\sin k R}{R} d x_{1}^{\prime} d x^{\prime} d x_{1} d x
\end{aligned}
$$

where

$$
R=\sqrt{\left(x-x^{\prime}\right)^{2}+\left(x_{1}-x_{1}^{\prime}\right)^{2}}
$$

Equation (11) can be rewritten as

$$
\begin{aligned}
\operatorname{Re} & {\left[Z_{m_{1} m_{2} m_{1}^{\prime} m_{2}^{\prime}}\right] } \\
& =\frac{k}{2 \pi} \sum_{m_{1}} \sum_{m_{2}} \sum_{m_{1}^{\prime} m_{2}^{\prime}} \sum_{m_{1} m_{2}} A_{m_{1}^{\prime} m_{2}^{\prime}} I_{m_{1} m_{2} m_{1}^{\prime} m_{2}^{\prime}} .
\end{aligned}
$$

The expression of the integral $I$ in (13) can be written as

$$
I_{m_{1} m_{2} m_{1}^{\prime} m_{2}^{\prime}}=\int_{0}^{L} \int_{0}^{L_{1}} \int_{0}^{L} \int_{0}^{L_{1}} \sin \frac{m_{1} \pi x}{L} \sin \frac{m_{2} \pi x_{1}}{L_{1}} \sin \frac{m_{1}^{\prime} \pi x^{\prime}}{L} \sin \frac{m_{2}^{\prime} \pi x_{1}^{\prime}}{L_{1}} \frac{\sin k R}{R} d x_{1}^{\prime} d x^{\prime} d x_{1} d x
$$

The quadruple integral of (14) is evaluated by using an established method given in [4]. $m_{1}^{\prime}, m_{2}^{\prime}, m_{1}$, and $m_{2}$ are modal indices.

An analytical equation to calculate the modal radiation efficiency as a function of frequency for a given input sound source is given as [7]

$$
\begin{gathered}
\sigma=\frac{W_{\text {rad }}}{W_{\text {in }}}, \\
W_{\text {in }}=\rho_{0} c_{0} S_{f}\langle\mathbf{w}\rangle^{2},
\end{gathered}
$$

where $W_{\text {rad }}$ is radiated sound power and $W_{\text {in }}$ is the plane wave sound radiation power by a piston source having the same surface area of the duct structure and vibrating with the same root mean square velocity as the structure $(\mathbf{w})$ [7]. $S_{f}$ is the flexible duct wall area and is given by $L \times L_{1}$, and vibration velocity of the structure is given by $\langle\mathbf{w}\rangle^{2}$.

\section{Numerical Model}

Numerical models based on FEM are developed to calculate the uncoupled structural and acoustic natural frequencies. Both of these models are linked for coupled analysis. Figure 3 shows the flow chart of numerical modelling procedure to calculate sound power radiation, modal radiation efficiency, and quadratic velocity.

3.1. Uncoupled Structural Model. Figure 4(a) shows the numerical model of a duct structure. A rectangular duct of dimensions $0.3 \mathrm{~m} \times 0.4 \mathrm{~m} \times 1.5 \mathrm{~m}\left(L_{1}=1.5, L_{2}=0.3\right.$, and $L_{3}=0.4$ ) with duct wall thickness of $5 \mathrm{~mm}$ is modelled and meshed using SHELL 63 elements [10]. A simply supported boundary condition is applied at both ends of the duct as shown in Figure 4(a). Aluminium material properties are applied to the structure and density $\rho_{s}=2770 \mathrm{~kg} / \mathrm{m}^{3}$, Young's modulus $E=71 \mathrm{GPa}$, Poisson's ratio $v=0.33$, and structural damping ratio $=0.01$ are considered.

3.2. Uncoupled Acoustic Model. An enclosed duct volume of dimensions $0.3 \mathrm{~m} \times 0.4 \mathrm{~m} \times 1.5 \mathrm{~m}$ is modelled and meshed using SOLID185 elements [10] as shown in Figure 4(b). Acoustic medium properties are as follows: $c_{0}=340 \mathrm{~m} / \mathrm{s}$, $\rho_{0}=1.225 \mathrm{~kg} / \mathrm{m}^{3}$, and acoustic damping ratio $=0.01$ are applied to acoustic volume. The boundaries of the acoustic cavity are assumed to be rigid in Figure 4(b).

3.3. Acoustic-Structural Coupled Model. Coupled model considers structural (duct) and acoustic (cavity) domains and these are solved in FEM acoustic module of LMS virtual lab-13 [11]. A constant velocity piston source excitation is applied to the inlet face of an acoustic mesh, which is shown in Figure 4(b). The coupled system of equations helps in determining structural displacements on the flexible circumferential duct walls and its pressure inside the duct.

3.4. Calculation of Sound Power Radiation. A numerical model to calculate sound radiated from the flexible duct walls is shown in Figure 5. The total sound power radiated from the duct walls is estimated using BEM acoustics exterior method. In the first step of BEM, acoustic potentials such as pressure and particle velocity are solved on the boundary mesh. In order to determine the sound radiated to the exterior of the duct, acoustic potentials are solved on the field point mesh which is a virtual surface surrounding the BE mesh. It is assumed that field point mesh is a nonreflecting surface where the wave just propagates and does not reflect. Figure 5 


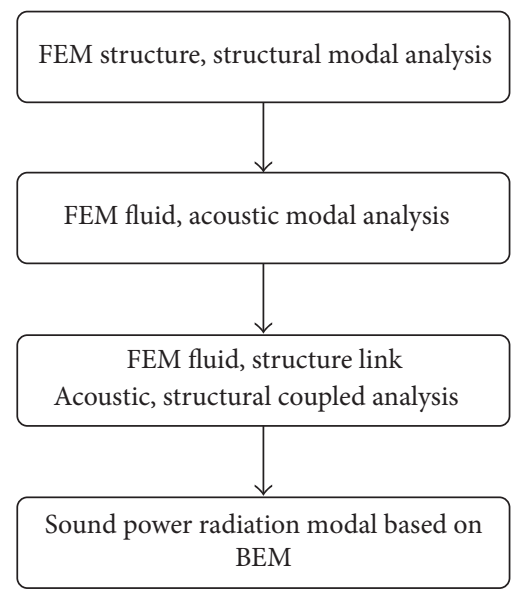

FIGURE 3: Flow chart of numerical modal to estimate sound power radiation.

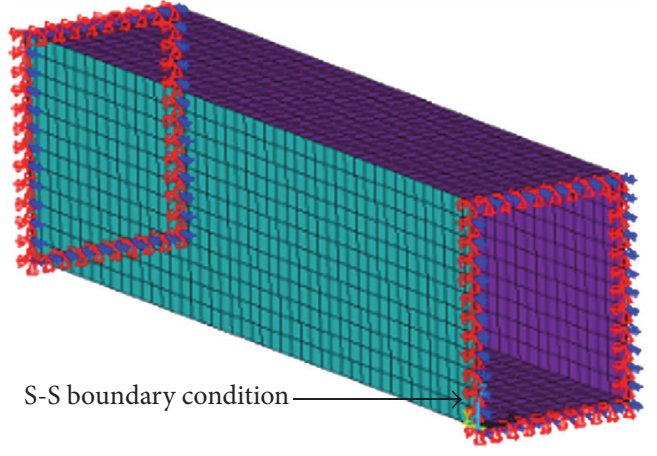

(a)

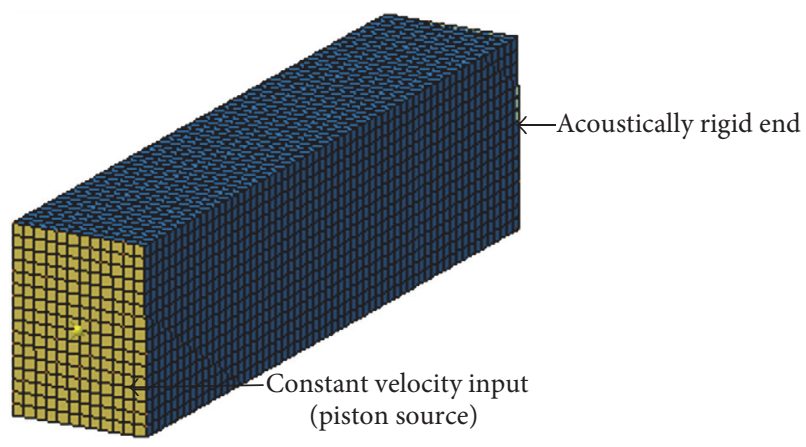

(b)

Figure 4: Numerical models to calculate the radiated sound power and radiation efficiency, (a) structural model and (b) acoustic model.

shows the boundary element mesh and field point mesh. The dimensions of the field point mesh are $0.4 \mathrm{~m} \times 0.5 \mathrm{~m} \times 1.5 \mathrm{~m}$.

Modal radiation efficiency is calculated numerically by activating selected structural or acoustic modes. A theoretical study can be performed to estimate radiation efficiency by choosing different combination of structural and acoustic modes participation in sound radiation. However, two cases are discussed; that is, (i) a single acoustic mode can be coupled to multiple structural modes and (ii) single structural mode can be coupled to the multiple acoustic modes.

\section{Results and Discussion}

The uncoupled structural modes of the duct structure are calculated by using the proposed equivalent plate model and compared to numerical results as discussed in Section 4.1. These uncoupled modes are classified into four groups based on the net volume displacement and symmetry behaviour at a particular mode which is described in Section 4.2. The uncoupled acoustic modes are calculated using the analytical model and compared to numerical results as shown in

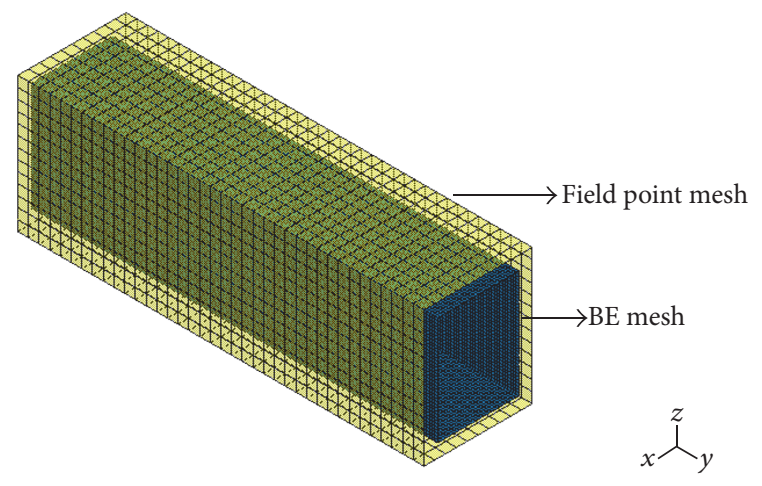

FIGURE 5: A numerical model to calculate the sound radiated from the flexible duct walls.

Section 4.3. Calculation of coupled modes and identification of strong coupling modes are based on transfer factor as discussed in Section 4.4. 
TABLE 1: First ten uncoupled structural modes of a rectangular duct with a simply supported boundary condition calculated with proposed analytical and numerical model.

\begin{tabular}{lcc}
\hline Mode & Analytical $(\mathrm{Hz})$ & Numerical $(\mathrm{Hz})$ \\
\hline 1 & 99.26 & 99.22 \\
2 & 114.65 & 114.59 \\
3 & 130.95 & 127.08 \\
4 & 140.59 & 140.51 \\
5 & 142.72 & 141.94 \\
6 & 163.98 & 163.47 \\
7 & 177.29 & 177.17 \\
8 & 195.67 & 189.68 \\
9 & 196.05 & 195.60 \\
10 & 209.76 & 208.72 \\
\hline
\end{tabular}

As the next step, modal radiation efficiencies are calculated by an equivalent plate model for all four groups and validated with the numerical results using the rectangular duct model. In the present paper, the comparisons are shown only for the strongly coupled modes (Section 4.5). In Section 4.6, duct modal radiation efficiencies calculated by the proposed method are compared to a simple rectangular plate available in literature. The behaviour of radiation efficiency when single acoustic mode coupled with multiple structural modes is studied and the results are shown in Section 4.7. The sound radiation behaviour is also studied and shown in Section 4.8.

4.1. Uncoupled Structural Modes. Table 1 shows the comparison of analytical and numerical results of the first ten uncoupled structural natural frequencies of a simply supported rectangular duct. It is observed that the analytical and numerical results are in a good agreement. An equivalent plate model is appropriate to explain the free vibration behaviour of a rectangular duct for further studies.

The structural modal analysis helps in understanding the displacement pattern of a structure subjected to a given boundary condition. The displacement pattern is expressed in terms of mode shape. Figures 6(b) and 6(d) show the developed surface of rectangular duct and its mode shape. The perimeter of the chosen duct dimensions is $1.4 \mathrm{~m}$ with length of $1.5 \mathrm{~m}$. Figures 6(a) and 6(b) show the comparison of analytical and numerical model results of fundamental duct mode shape. Similarly, Figures 6(c) and 6(d) show the 10th mode shape. Analytical mode shapes shown in Figures 6(b) and $6(\mathrm{~d})$ are equivalent plate model results. It is observed from the figure that both analytical and numerical model results have the same behaviour.

4.2. Mode Shapes Representation, Grouping and Calculating Net Volume Displacement. The structural mode shapes of the duct are analysed to understand the free vibration behaviour of the rectangular duct, symmetry behaviour, and relative change of phase between the panel pairs.

A particular notation has been followed to describe each mode shape in terms of natural frequency, the number of antinodes on panel pairs, and symmetry behaviour. The fundamental structural mode shape shown in Figure 6(a) can be represented according to the proposed notation as $\left[D \_S(1,1), S(1,1)\right]_{99.2 \mathrm{~Hz}}$. It can be described as follows: the first term in the bracket indicates the number of antinodes on $x$-panel pairs, that is, at $x=0.5 L_{2}$ (plate $P_{2}$ ) and $x=$ $-0.5 L_{2}$ (plate $P_{4}$ ) along $y$ - and $z$-directions, and for the given example $(1,1)$ means one antinode in $y$ - and $z$-directions. The second term indicates the number of antinodes on $y$ panel pairs, that is, at $y=0.5 L_{3}$ (plate $P_{1}$ ) and $y=$ $-0.5 L_{3}$ (plate $P_{3}$ ) along $x$ - and $z$-directions. Letter " $D$ " indicates the dominating pair which can be identified by comparing the modal displacement amplitude between the pair of plate panels. Letter " $S$ " denotes symmetry of the mode shape behaviour of duct walls and end number is the modal frequency.

Similarly, the 10th mode shape can be represented as $[S(2,2), \text { D_AS }(1,2)]_{209.72 \mathrm{~Hz}}$. Here, the number of antinodes on $x$-panel pairs (i.e., on $P_{2}$ and $\left.P_{4}\right)$ is $(2,2)$ and the number of antinodes on $y$-panel pairs (that is on $P_{1}$ and $\left.P_{3}\right)$ is $(1,2)$. Dominant amplitude $(\mathrm{D})$ is on $y$-panel pair. Letter "AS" denotes antisymmetry mode shape behaviour of duct walls. So, based on this proposed notation, the modes are categorized into four groups based on mode symmetry and antisymmetry behaviour. Group 1 represents Symmetry (S)-Symmetry (S) behaviour of $x$-axis pair and $y$-axis pair. Similarly, the other three groups are S-AS, AS-S, and AS-AS.

Net volume displacement for each uncoupled structural mode is calculated with (16). It helps to understand efficiently radiating sound modes and types of sound source

$$
v_{m}=\sum_{n=1}^{4}\left(\sum_{m} \Delta v_{m}\right)_{n},
$$

where $n$ represents panel number varying from 1 to 4 which are considered as four walls of the duct. $\Delta v_{m}$ is volume displacement associated with amplitude displacement of the $m$ th element in an $n$th plate, that is, each duct wall [7].

First, thirty modes of a simply supported rectangular duct are classified into four groups and net volume displacement of each mode is calculated according to (16). These results are given in Table 2. It is observed that modes in group 2, group 3, and group 4 have zero net volume displacement. The modes with odd modal index in group 1 (odd, odd) have higher net volume displacement values than the remaining modes in the group. The modes which have the symmetrical panel pairs and the largest net volume displacement in group 1 are efficient sound radiators and also identified as monopole type of sound source. Modes having (odd, even) or (even, odd) mode shapes in group 1 behave as a dipole sound source and are less efficient sound radiators. Sound radiation behavior is observed by calculating radiation efficiency and their slope.

4.3. Uncoupled Acoustic Modes. The uncoupled acoustical modes for the duct volume subjected to rigid termination boundary conditions are calculated analytically and numerically. Table 3 shows a comparison of first ten uncoupled acoustical modes of the duct. The first acoustic mode wavelength is equal to two times the largest dimension. In this case, it is $113.3 \mathrm{~Hz}$ in the longitudinal direction. It is observed 


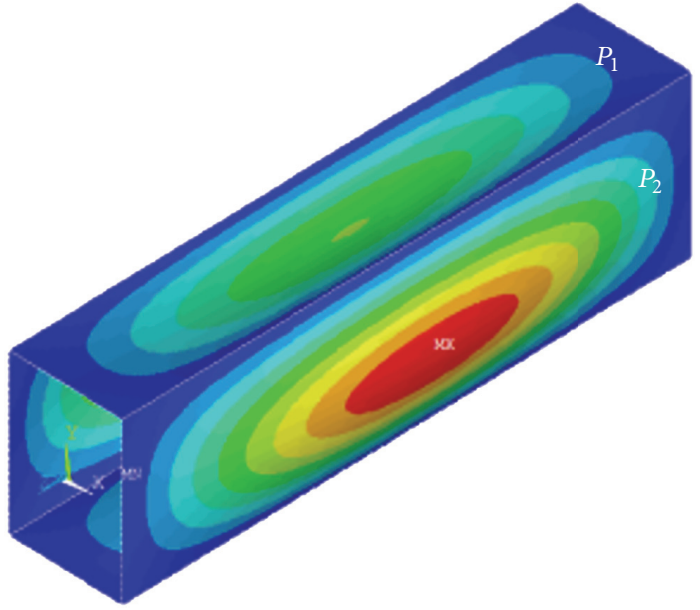

(a)

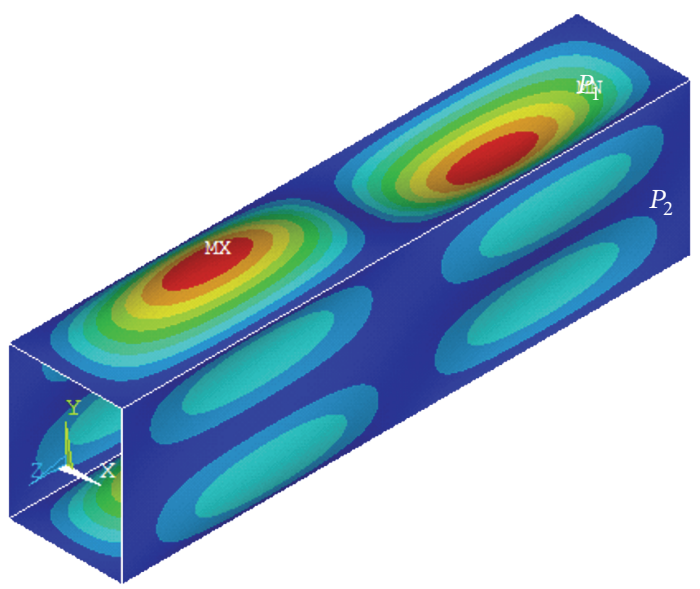

(c)

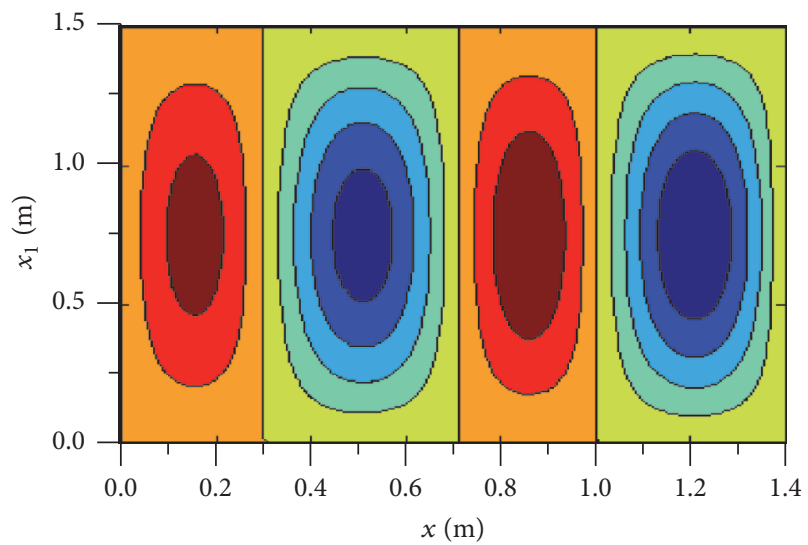

(b)

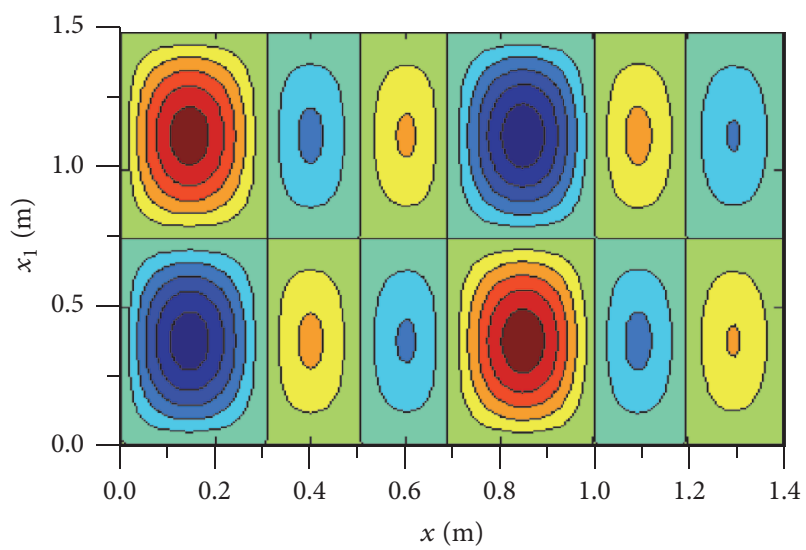

(d)

FIGURE 6: (a) Fundamental structural duct mode shape at $99.22 \mathrm{~Hz}$, numerical. (b) Fundamental structural duct mode shape at $99.26 \mathrm{~Hz}$, analytical. (c) Tenth duct mode shape at $208.72 \mathrm{~Hz}$, numerical. (d) Tenth duct mode shape at $209.76 \mathrm{~Hz}$, analytical.

that the uncoupled acoustic modes estimated analytically and numerically are in a good agreement.

4.4. Comparison of Coupled and Uncoupled Response. The sound pressure inside the duct is calculated by both analytical and numerical method for the coupled and uncoupled cases. Equation (7) from the analytical model is used to calculate the inside duct pressure. Variation of the sound pressure inside the duct at a location $\left(0.5 \times L_{2}, 0.5 \times L_{3}, 0.4 \times L_{1}\right)$ with respect to frequency for coupled and uncoupled analysis is shown in Figures 7(a) and 7(b). A good agreement between both numerical and analytical results is observed for inside pressure calculation as shown in Figure 7(a).

Figure 7(b) shows the sound pressure inside the duct for coupled and uncoupled conditions. It is observed from the graph that the first peak in a pressure spectrum, based on an uncoupled model occurring at $113.3 \mathrm{~Hz}$, corresponds to the uncoupled acoustic mode. Similarly, two pressure peaks in the coupled model are observed at $105 \mathrm{~Hz}$ and $122 \mathrm{~Hz}$. The energy exchange between acoustic and structural subsystems at coupling frequency converts into a multidegree freedom system. Similarly, at $226 \mathrm{~Hz}$ it is divided into two coupled frequencies, each at $220 \mathrm{~Hz}$ and $228 \mathrm{~Hz}$.

Table 4(a) gives the first thirty coupled modes which are estimated numerically by coupled modal analysis. These coupled modes contain both acoustical and structural modes. It can be observed that coupling occurs close to the acoustical modes.

Table 4(b) shows the comparison of uncoupled and coupled modes of a rectangular duct. It shows that an acoustic mode at $113.3 \mathrm{~Hz}$ and a structural mode at $114.59 \mathrm{~Hz}$ are strongly coupled, and a shift in a natural frequency leads to coupled modes at $105.36 \mathrm{~Hz}$ and $121.47 \mathrm{~Hz}$. Similarly, the acoustic mode at $226.6 \mathrm{~Hz}$ is coupled with the structural mode at $224.69 \mathrm{~Hz}$ and leads to 219.39 and $226.30 \mathrm{~Hz}$ coupled modes. There also exists strong coupling of a structural mode at $345.1 \mathrm{~Hz}$ and an acoustical mode at $340 \mathrm{~Hz}$ which results in coupled modes at $343.82 \mathrm{~Hz}$ and $347.07 \mathrm{~Hz}$. 


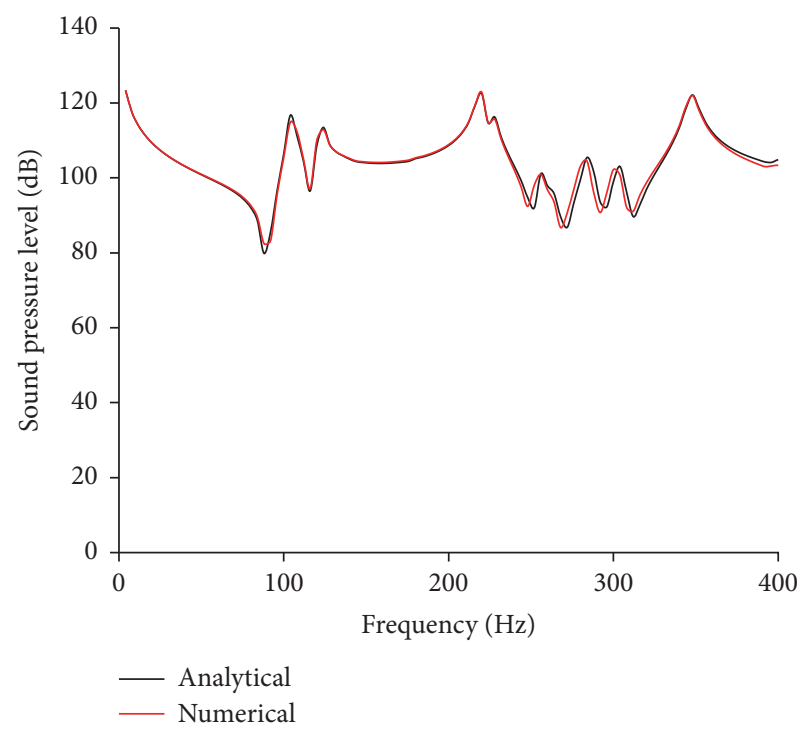

(a)

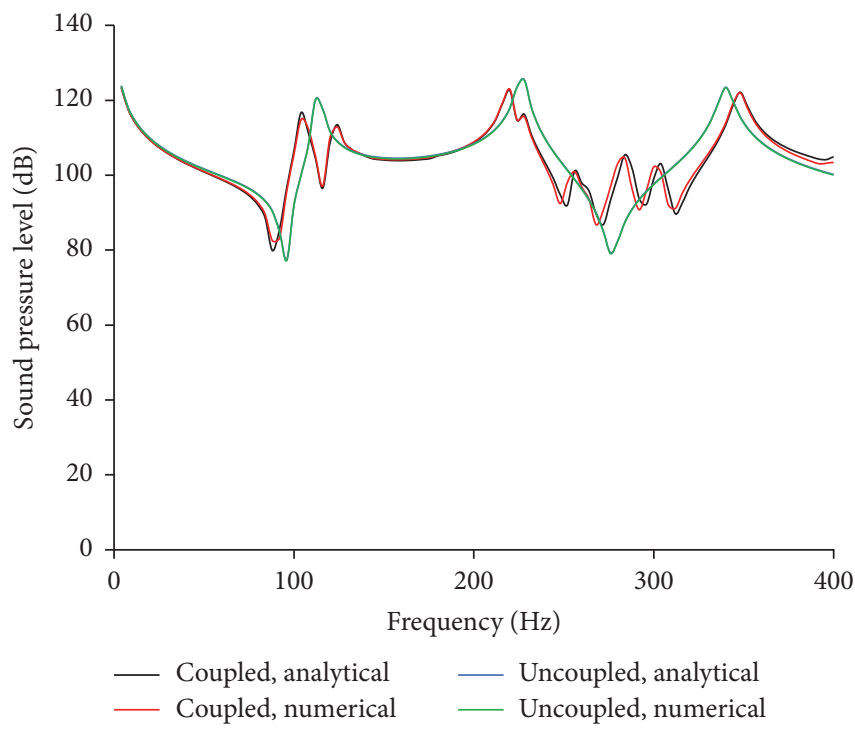

(b)

Figure 7: (a) Variation of inside duct pressure with respect to frequency for coupled analysis. (b) Comparison of uncoupled and coupled pressure inside the duct.

TABLE 2: Duct mode group classification and net volume displacements for each mode.

\begin{tabular}{|c|c|c|c|}
\hline & Mode number & & Net volume displacement \\
\hline \multirow{13}{*}{ Group 1} & 1 & {$\left[\mathrm{D} \_\mathrm{S}(1,1), \mathrm{S}(1,1)\right]_{99.2 \mathrm{~Hz}}$} & 0.1182 \\
\hline & 2 & {$\left[D \_S(1,2), S(1,2)\right]_{114.59 \mathrm{~Hz}}$} & 0 \\
\hline & 4 & {$\left[\mathrm{D} \_S(1,3), S(1,3)\right]_{140.5 \mathrm{~Hz}}$} & 0.0421 \\
\hline & 7 & {$\left[\mathrm{D} \_S(1,4), S(1,4)\right]_{177.17 \mathrm{~Hz}}$} & 0 \\
\hline & 11 & {$\left[\mathrm{D} \_\mathrm{S}(1,5), \mathrm{S}(1,5)\right]_{224.69 \mathrm{~Hz}}$} & 0.0277 \\
\hline & 14 & {$\left[S(1,1)^{*}, \text { D_S }(1,1)\right]_{248.96 \mathrm{~Hz}}$} & 0.2630 \\
\hline & 16 & {$\left[S(1,2)^{*}, \text { D_S }(1,2)\right]_{259.43 \mathrm{~Hz}}$} & 0 \\
\hline & 18 & {$\left[S(1,3)^{*}, \text { D_S }(1,3)\right]_{278.08 \mathrm{~Hz}}$} & 0.0868 \\
\hline & 19 & {$\left[\mathrm{D} \_S(1,6), S(1,6)\right]_{283.08 \mathrm{~Hz}}$} & 0 \\
\hline & 21 & {$\left[\mathrm{~S}(1,4)^{*}, \mathrm{D} \_\mathrm{S}(1,4)\right]_{306.25 \mathrm{~Hz}}$} & 0 \\
\hline & 23 & {$\left[S(1,5)^{*}, \text { D_S }(1,5)\right]_{345.11 \mathrm{~Hz}}$} & 0.0512 \\
\hline & 24 & {$\left[\mathrm{D} \_S(1,7), S(1,7)\right]_{352.37 \mathrm{~Hz}}$} & 0.0216 \\
\hline & 29 & {$\left[S(1,6)^{*}, D_{-} S(1,6)\right]_{395,46 \mathrm{~Hz}}$} & 0 \\
\hline \multirow{7}{*}{ Group 2} & 3 & {$\left[\mathrm{D} \_A S(1,1), S(2,1)\right]_{127.08 \mathrm{~Hz}}$} & 0 \\
\hline & 5 & {$\left[\mathrm{D} \_A S(1,2), S(2,2)\right]_{141.94 \mathrm{~Hz}}$} & 0 \\
\hline & 6 & {$\left[\mathrm{D} \_A S(1,3), S(2,3)\right]_{163.47 \mathrm{~Hz}}$} & 0 \\
\hline & 9 & {$\left[\mathrm{D} \_A S(1,4), S(2,4)\right]_{195.60 \mathrm{~Hz}}$} & 0 \\
\hline & 13 & {$[\text { D_AS }(1,5), S(2,5)]_{239.22 \mathrm{~Hz}}$} & 0 \\
\hline & 20 & {$\left[D \_A S(1,6), S(2,6)\right]_{294.53 \mathrm{~Hz}}$} & 0 \\
\hline & 25 & {$\left[\mathrm{D} \_S(1,7), S(2,7)\right]_{361.47 \mathrm{~Hz}}$} & 0 \\
\hline \multirow{6}{*}{ Group 3} & 8 & {$[S(2,1), \text { D_AS }(1,1)]_{189.68 \mathrm{~Hz}}$} & 0 \\
\hline & 10 & {$[S(2,2), \text { D_AS }(1,2)]_{208.72 \mathrm{~Hz}}$} & 0 \\
\hline & 12 & {$[S(2,3), \text { D_AS }(1,3)]_{233.06 \mathrm{~Hz}}$} & 0 \\
\hline & 17 & {$[S(2,4), \text { D_AS }(1,4)]_{267.39 \mathrm{~Hz}}$} & 0 \\
\hline & 22 & {$[S(2,5), \text { D_AS }(1,5)]_{312.34 \mathrm{~Hz}}$} & 0 \\
\hline & 26 & {$[S(2,6), \text { D_AS }(1,6)]_{368.20 \mathrm{~Hz}}$} & 0 \\
\hline \multirow{2}{*}{ Group 4} & 27 & {$\left[\mathrm{D} \_\mathrm{AS}(2,2), \mathrm{AS}(2,2)\right]_{375.41 \mathrm{~Hz}}$} & 0 \\
\hline & 30 & {$\left[\mathrm{D} \_\mathrm{AS}(2,3), \mathrm{AS}(2,3)\right]_{403.43 \mathrm{~Hz}}$} & 0 \\
\hline
\end{tabular}


TABLE 3: First ten uncoupled acoustic modes of a rectangular duct volume with rigid end condition.

\begin{tabular}{lcc}
\hline Mode number & Analytical $(\mathrm{Hz})$ & Numerical $(\mathrm{Hz})$ \\
\hline 1 & 113.3 & 113.3 \\
2 & 226.7 & 226.6 \\
3 & 340 & 340 \\
4 & 425 & 425 \\
5 & 439.9 & 439.8 \\
6 & 453.3 & 453.3 \\
7 & 481.7 & 481.6 \\
8 & 544.3 & 544.2 \\
9 & 566.7 & 566.6 \\
10 & 566.7 & 566.6 \\
\hline
\end{tabular}

The fundamental acoustic mode at $113.3 \mathrm{~Hz}$ is closer to second structural mode at $114 \mathrm{~Hz}$, and the second acoustic mode $(226.6 \mathrm{~Hz})$ is strongly coupled to $11 \mathrm{th}, 14 \mathrm{th}$, and $17 \mathrm{th}$ $(224 \mathrm{~Hz}, 248.96 \mathrm{~Hz}$, and $279.36 \mathrm{~Hz})$ structural modes. The third acoustic mode is strongly coupled to 20th structural mode at $307.82 \mathrm{~Hz}$. Table 5 shows the transfer factor values for the strongly coupled acoustic modes. It is observed from the table that a strong coupling exists between an acoustic mode at $113.3 \mathrm{~Hz}$ and structural mode at $114.7 \mathrm{~Hz}$. Transfer factor values are close to one representing a strong coupling. Generally, lesser difference in uncoupled acoustic and structural natural frequencies and good spatial matching of the mode shapes provide higher transfer factor values.

4.5. Calculation of Radiation Efficiency for Strongly Coupled Structural Modes. Based on transfer factor values, the structural mode frequencies with highest transfer factor are identified and these coupled modes are considered for sound power radiation calculation and then radiation efficiency. Figure 8 shows the radiation efficiencies of one structural mode coupled to multiple acoustic modes calculated both analytically and numerically. It shows that both analytical and numerical results are in good agreement. It is clear that equivalent plate model can be used effectively to calculate the modal radiation efficiency.

It is observed from Figure 8 that mode $14(248.96 \mathrm{~Hz})$ is the most efficient radiating mode followed by mode 1 $(99.26 \mathrm{~Hz})$. It is also observed that net volume displacement of mode 14 is large when compared to other modes (Table 2). This is due to substantial net volume displacement and symmetry between the panel pairs of mode 14 at $248.96 \mathrm{~Hz}$. Similarly, structural modes $(1,11,14$, and 18$)$ at $99.2 \mathrm{~Hz}$, $248.96 \mathrm{~Hz}, 224.69 \mathrm{~Hz}$, and $283.08 \mathrm{~Hz}$ have the same kind of slopes, which is a characteristic observed in (odd, odd) mode. A slope of $20 \mathrm{~dB} /$ decade is observed in (odd, odd) modes. Individual groups such as S-S (group 1) with (odd, odd) indices are the effective sound radiators. Structural modes (2, 21) at $114.65 \mathrm{~Hz}$ and $306.25 \mathrm{~Hz}$ are (odd, even) modes and have a slope of $40 \mathrm{~dB} /$ decade.
Table 6 shows the slopes of strongly coupled structural modes and comparison of slopes for analytical and numerical models. It shows that both results are in good agreement.

4.6. Comparison of Duct Radiation Efficiencies with a Plate. The radiation efficiency of a duct is compared to a plate radiation efficiency so as to understand the correlation and approximate duct sound radiation behaviour. A simply supported plate with equivalent dimensions of the duct's perimeter and length is considered for the comparison. Modal radiation efficiency for a simply supported rectangular plate can be calculated using analytical equations given in [6]. Critical frequency for a simply supported rectangular plate can be calculated using (17) as given in [6]

$$
\omega_{c}=c_{0}^{2}\left(\frac{\rho_{s} h}{D}\right)^{1 / 2},
$$

where $c_{o}$ is the speed of sound, $\rho_{s} h$ is the surface density, and $D$ is the flexure rigidity.

Modal radiation efficiencies for the duct are calculated for one structural mode coupled to multiple acoustic modes which exist within the critical frequency. These calculated radiation efficiencies are compared to radiation efficiency of a simply supported plate with dimensions of $(1.4 \mathrm{~m} \times$ $1.5 \mathrm{~m}$ ). Figures 9-12 show the comparison of the duct modal radiation efficiencies with the plate modal radiation efficiency for the four different groups.

Figure 9 shows the modal radiation efficiency comparison of $(1,1)$ plate with the [D_S, S] group modes. All the modes in group 1 with (odd, odd) modal indices exhibit the same slope of $20 \mathrm{~dB} /$ decade as that of a simply supported plate $(1.4 \mathrm{~m} \times 1.5 \mathrm{~m})$ until the critical frequency. After that, the curve becomes asymptotic and the radiation efficiency curve approaches unity.

Figure 10 shows the variation of modal radiation efficiencies corresponding to [D_AS, S] group and comparison with that of a simply supported plate of $(2,1)$ mode. The slope of radiation efficiency in group 2 is high when compared to group 1. Similarly, volume displacement in group 2 is less compared to group 1. A plate with equivalent dimensions has the same slope as a duct with group 2 mode shapes, but it has a higher slope when compared to the lower mode in the same group. The slope behaviour of $40 \mathrm{~dB} / \mathrm{decade}$ is observed until the critical frequency, after which the values approach unity, and the curve becomes asymptotic. It is also observed that radiation efficiency values are lower for the higher modes when compared to the fundamental mode.

Figure 11 shows the variation of modal radiation efficiencies corresponding to [S, D_AS] and comparison with that of a simply supported plate of $(1,2)$ mode. The slope values of this group are the same as [D_AS, S] group. It exhibits that both groups have similar radiation curves. These groups have slope behaviour the same as a simply supported plate $(1,2)$ mode with a value of $40 \mathrm{~dB} /$ decade until critical frequency.

Figure 12 shows the comparison of modal radiation efficiency of [D_AS, AS] group with simply supported plate mode of $(2,2)$. All the modes in this group have (even, even) modal indices and exhibit similar slope to that of a simply 
TABLE 4: (a) Coupled modes of a rectangular duct. (b) Comparison of uncoupled and coupled modes of a rectangular duct.

(a)

\begin{tabular}{lccccc}
\hline Mode number & Frequency $(\mathrm{Hz})$ & Mode number & Frequency $(\mathrm{Hz})$ & Mode number & Frequency $(\mathrm{Hz})$ \\
\hline 1 & 100.48 & 11 & 208.23 & 21 & 22 \\
2 & 105.36 & 12 & 219.39 & 232.82 & 294.39 \\
3 & 121.47 & 13 & 226.30 & 24 & 301.62 \\
4 & 126.61 & 14 & 232.59 & 25 & 311.92 \\
5 & 140.08 & 15 & 258.81 & 26 & 343.82 \\
6 & 141.47 & 16 & 258.02 & 27 & 347.07 \\
7 & 162.99 & 17 & 260.92 & 28 & 352.22 \\
8 & 177.12 & 18 & 266.91 & 29 & 361.28 \\
9 & 189.14 & 19 & 282.74 & 30 & 367.71 \\
10 & 195.22 & 20 & & 374.89 \\
\hline
\end{tabular}

(b)

\begin{tabular}{lcc}
\hline Uncoupled mode frequency $(\mathrm{Hz})$ & Mode type & Coupled mode frequency $(\mathrm{Hz})$ \\
\hline 99.22 & Structural & 100.48 \\
113.3 & Acoustic & 105.36 \\
114.59 & Structural & 121.47 \\
127.08 & Structural & 126.61 \\
140.51 & Structural & 140.08 \\
141.94 & Structural & 141.47 \\
163.47 & Structural & 162.99 \\
177.17 & Structural & 177.12 \\
189.68 & Structural & 189.14 \\
195.60 & Structural & 195.22 \\
208.72 & Structural & 208.23 \\
224.69 & Structural & 219.39 \\
226.6 & Acoustic & 226.30 \\
345.1 & Structural & 343.82 \\
345 & Acoustic & 347.07 \\
\hline
\end{tabular}

TABLE 5: Transfer factor values of strongly coupled acoustic modes.

\begin{tabular}{lcc}
\hline Acoustic mode $(\mathrm{Hz})$ & Structural mode $(\mathrm{Hz})$ & Transfer factor $T_{n, m}$ \\
\hline 113.3 & 114.7 & 0.99 \\
& 224.9 & 0.98 \\
226.6 & 248.96 & 0.66 \\
& 278.08 & 0.57 \\
340 & 306.06 & 0.79 \\
\hline
\end{tabular}

supported plate $(1.4 \mathrm{~m} \times 1.5 \mathrm{~m})$ with $60 \mathrm{~dB} /$ decade for group (even, even) modal indices. The slopes of these curves are the highest when compared to any other group.

Table 7 shows the comparison of slope values of all the four groups for a few selected duct modes and simply supported plate modes. Duct radiation efficiency slope values of all groups are the same as an equivalent plate. It can be observed from Figures 9-12 that the radiation efficiency curves for single structural mode coupled to multiple acoustic modes and plate mode behaviour are found to be similar.
Therefore, it can be concluded that duct radiation efficiencies of different groups can be calculated based on an equivalent plate model with minimum error. Equivalent plate model for a rectangular duct proposed in this research work is an appropriate way to predict the free vibration behaviour and sound radiation characteristic of a duct.

4.7. Calculation of Radiation Efficiency for One Acoustic Mode Coupled to Multiple Structural Modes. In order to understand the effect of coupling closer to an acoustic mode, a case of one acoustic mode coupled to multiple structural modes has been studied. Figure 13 shows the radiation efficiency of three acoustic modes such as 113,226 , and $339 \mathrm{~Hz}$ frequencies that are individually coupled to all structural modes with respect to frequency.

4.8. Total Radiation Efficiency and Radiated Sound Power. Figures 14 and 15 show the total radiation efficiency and sound power radiated from multiple acoustic modes when coupled to multiple structural modes. All peaks in the sound 
TABLE 6: Radiation efficiency slopes of strongly coupled structural modes.

\begin{tabular}{lccc}
\hline Mode & Frequency $(\mathrm{Hz})$ & Analytical (dB/decade) & Numerical (dB/decade) \\
\hline 1 & 99.26 & 19.42 & 18.90 \\
2 & 114.65 & 39.25 & 39.00 \\
11 & 224.84 & 17.27 & 16.96 \\
14 & 249.85 & 18.72 & 18.74 \\
18 & 278.08 & 16.75 & 16.90 \\
21 & 306.25 & 38.05 & 38.69 \\
\hline
\end{tabular}

TABLE 7: Comparison of the radiation efficiency slopes for duct modes and simply supported plate modes.

\begin{tabular}{lcccc}
\hline Group & Duct mode & $\begin{array}{c}\text { Duct mode analytical } \\
(\mathrm{dB} / \text { decade })\end{array}$ & $\begin{array}{c}\text { Duct mode numerical } \\
\text { (dB/decade) }\end{array}$ & $\begin{array}{c}\text { Simply supported plate } \\
\text { mode }(\mathrm{dB} / \text { decade })\end{array}$ \\
\hline 1 & {$\left[\mathrm{D} \_\mathrm{S}(1,1), \mathrm{S}(1,1)\right]_{99.2 \mathrm{~Hz}}$} & 19 & 19 & 19 \\
2 & {$\left[\mathrm{D} \_\mathrm{AS}(1,1), \mathrm{S}(2,1)\right]_{127.08 \mathrm{~Hz}}$} & 41 & 41 & 39 \\
3 & {$\left[\mathrm{~S}(2,3), \mathrm{D}_{\mathrm{AS}(1,3)}\right]_{233.06 \mathrm{~Hz}}$} & 37 & 39 & 39 \\
4 & {$\left[\mathrm{D} \_\mathrm{AS}(2,2), \mathrm{AS}(2,2)\right]_{375.41 \mathrm{~Hz}}$} & 57 & 58 & 54 \\
\hline
\end{tabular}

power curve are associated with the coupled modes. First peak in the total sound power curve occurs at fundamental acoustic mode $113.3 \mathrm{~Hz}$. Second prominent peak in the curve occurs close to second acoustic mode at $226.6 \mathrm{~Hz}$ where acoustic energy is exchanged between three structural modes. Third prominent peak occurs close to third acoustic mode at $340 \mathrm{~Hz}$. It is observed that second acoustic mode is more efficient in radiating sound due to strong coupling amongst three structural modes as compared to the other two acoustical modes.

Figure 16 represents pressure distribution at a point on $x$-panel $(x=0.2 \mathrm{~m}, y=0 \mathrm{~m}$, and $z=0.75 \mathrm{~m})$ and $y$ panel $(x=0 \mathrm{~m}, y=0.25 \mathrm{~m}$, and $z=0.75 \mathrm{~m})$, respectively. All the peaks correspond to coupled frequencies. Figure 17 represents numerical results of the sound radiation pattern of first three coupled acoustic modes at $113 \mathrm{~Hz}, 226 \mathrm{~Hz}$, and $340 \mathrm{~Hz}$. For the third acoustic mode, radiation pattern is similar to structural mode shape $(306 \mathrm{~Hz})$, where a strong coupling is observed and has a dipole behaviour.

It is observed from previous results that both analytical and numerical results are in good agreement to capture the acoustic and structural behaviour of both coupled and uncoupled subsystems. The proposed equivalent plate model for rectangular duct predicted free vibration behaviour and sound radiation characteristics. Modal grouping based on free vibration study shows that group 1 (SymmetrySymmetry) modes with (odd, odd) indices are more effective sound radiators and thus justified based on radiation efficiency results.

\section{Conclusions}

Analytical and numerical models for calculating rectangular duct sound radiation characteristics have been discussed in the present manuscript. The predicted results from two

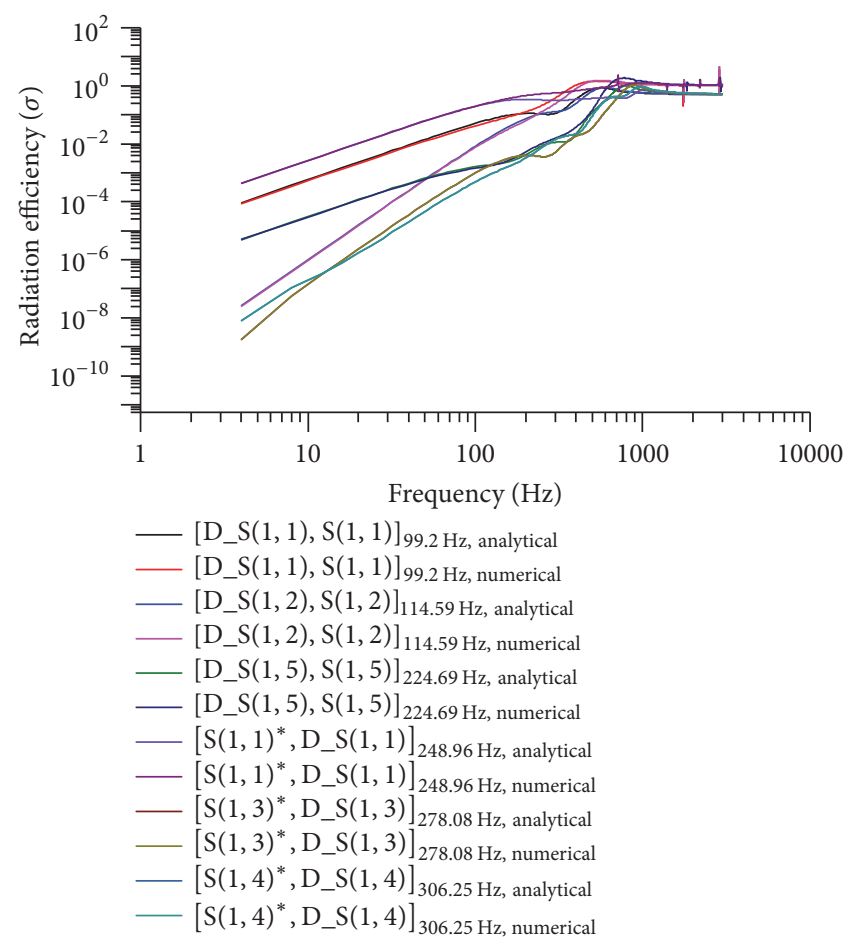

FIGURE 8: Modal radiation efficiency of the strongly coupled structural modes.

models are in good agreement. It has been verified that rectangular duct considered in this paper can be modelled as an equivalent plate for free vibration analysis. The uncoupled structural duct modes have been categorized into four groups and it was found that Symmetry-Symmetry mode group with (odd, odd) modal indices behave as efficient sound radiators. These were determined from higher net volume 


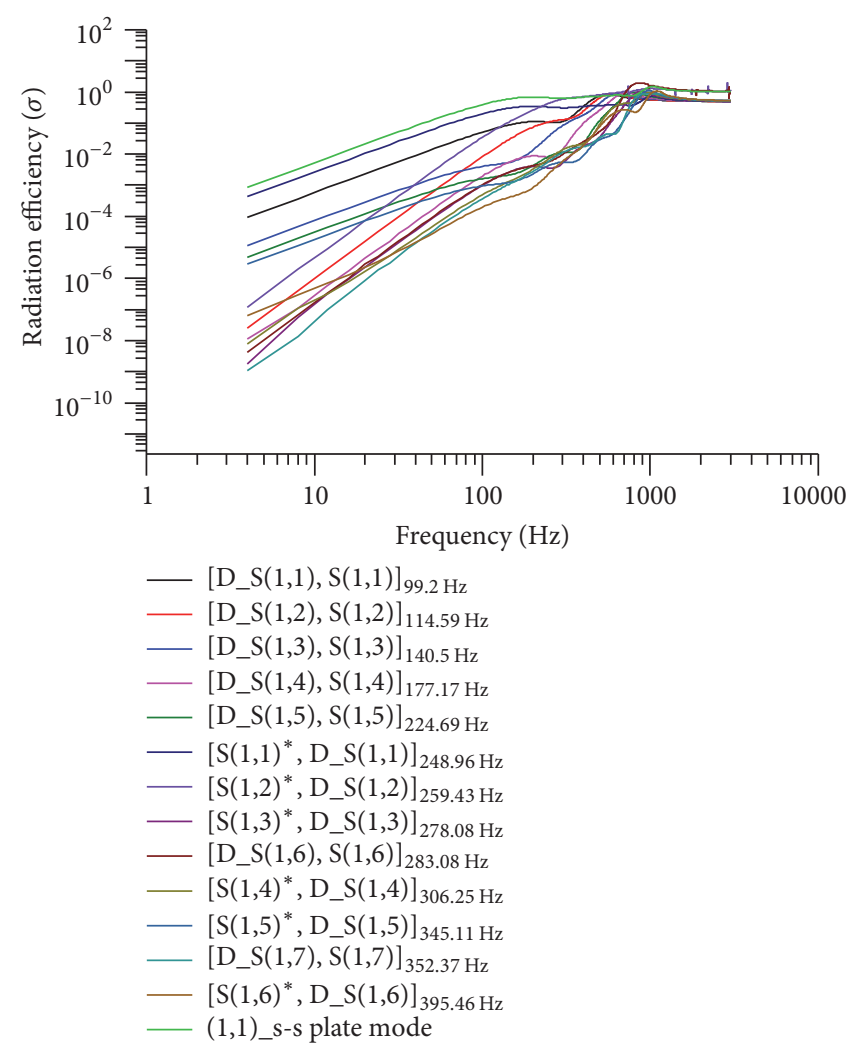

FIGURE 9: Calculation of duct modal radiation efficiency with respect to frequency for [(D_S, S)] group and plate mode $(1,1)$.

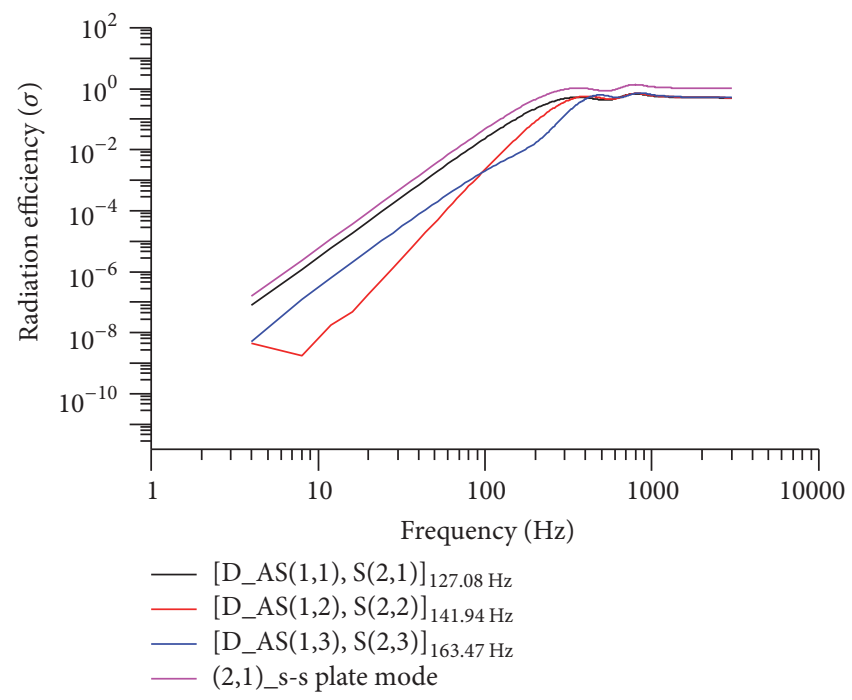

FIGURE 10: Calculation of duct modal radiation efficiency with respect to frequency for [D_AS, S] group and plate mode $(2,1)$.

displacement of (odd, odd) modes when compared to others. An analytical model of the total sound power radiated from duct walls has been validated with numerical results. Duct radiation pattern is similar to standard sound sources such as monopole and dipole. The effect of acoustic and structural mode coupling on radiation efficiency has been studied and compared to a simply supported plate behaviour. Slope of radiation efficiency curves for four duct mode groups have 


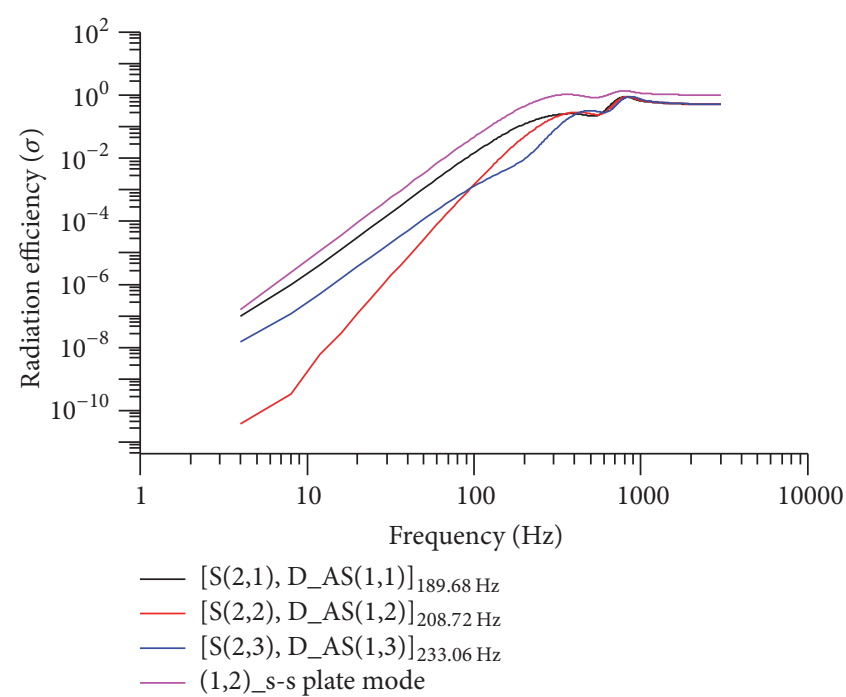

FIGURE 11: Calculation of duct modal radiation efficiency with respect to frequency for [S, D_AS] group and $(1,2)$ plate mode.

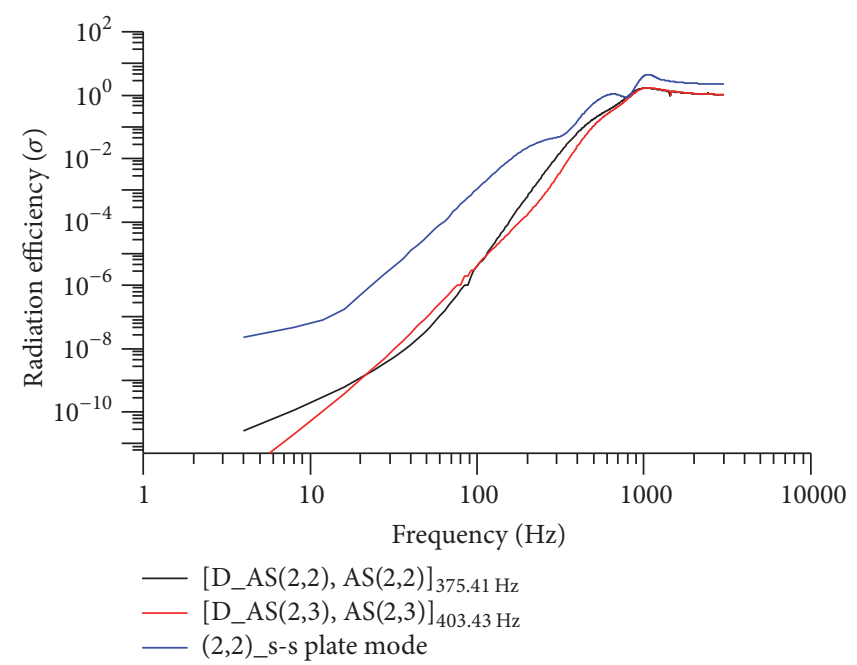

FIGURE 12: Calculation of duct modal radiation efficiency with respect to frequency for ([D_AS, AS ]) and $(2,2)$ plate mode.

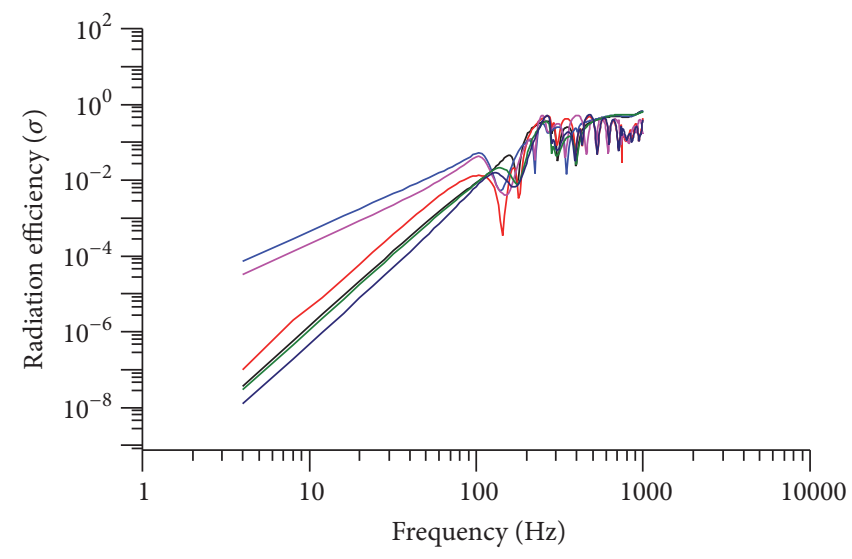

— Mode 1_113_Hz, analytical

- Mode 1_113_Hz, numerical

- Mode 2_226_Hz, analytical

- Mode 2_226_Hz, numerical

— Mode 3_339_Hz, analytical

- Mode 3_339_Hz, numerical

FIGURE 13: Radiation efficiency of the first three acoustic modes coupled with multiple structural modes (numerical versus analytical). 


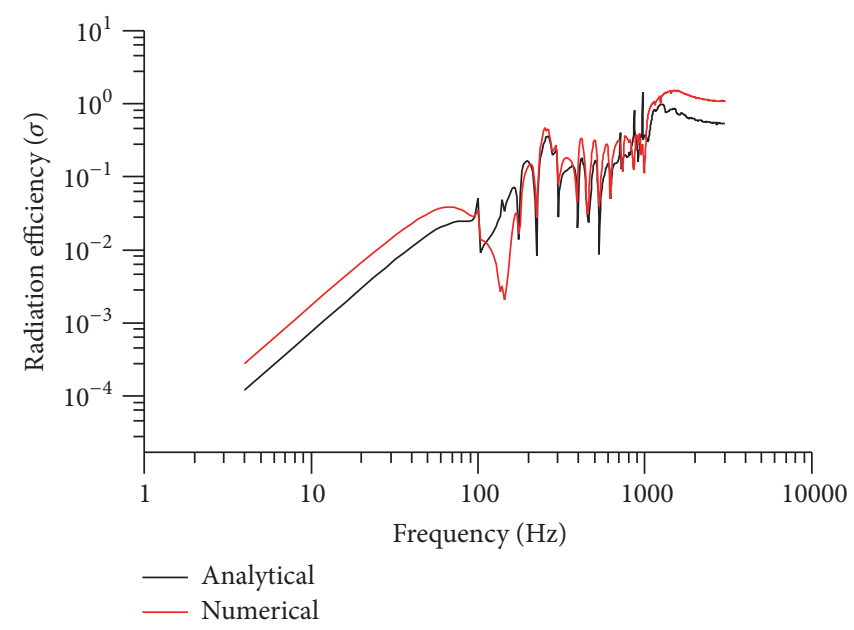

FIGURE 14: Total radiation efficiency of the rectangular duct (numerical versus analytical).

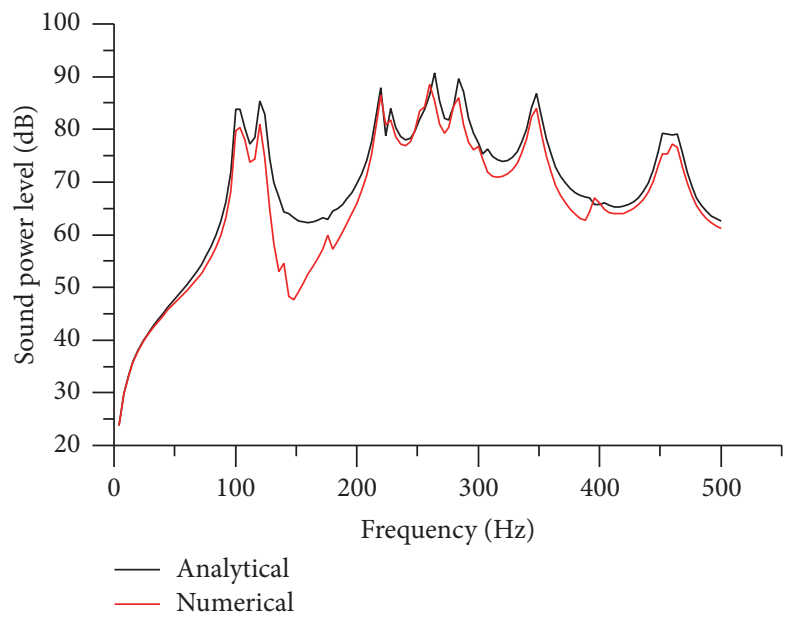

FIGURE 15: Total sound power radiated from the rectangular duct.

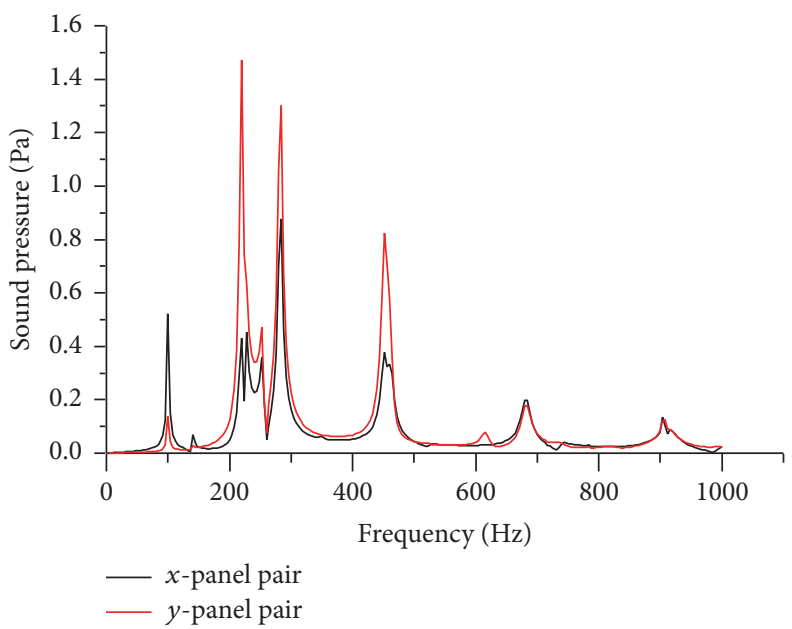

FIGURE 16: Sound pressure at field point on $x$-panel pair $(0.35 \mathrm{~m}, 0.75 \mathrm{~m}$, and $0.25 \mathrm{~m})$ and $z$-panel pair $(0.15 \mathrm{~m}, 0.75 \mathrm{~m}$, and $0.45 \mathrm{~m})$. 

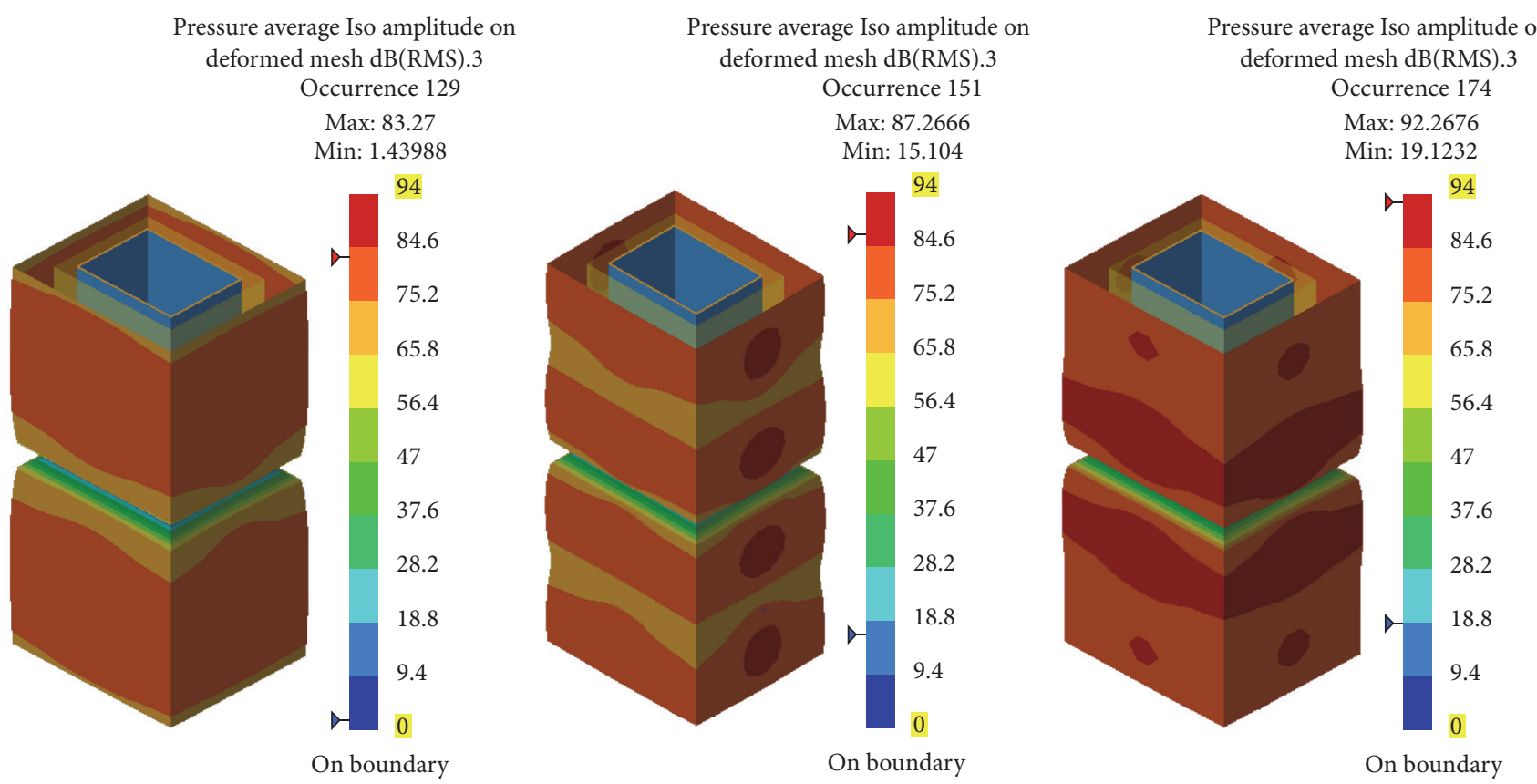

FIGURE 17: Sound radiation pattern of the first three coupled acoustic modes at $113 \mathrm{~Hz}, 226 \mathrm{~Hz}$, and $340 \mathrm{~Hz}$.

been compared to simply supported plate curves. It has been shown that sound radiation efficiency of the rectangular duct is similar to a plate.

\section{Competing Interests}

The authors declare that they have no competing interests.

\section{Acknowledgments}

The authors would like to thank Indian Institute of Technology Hyderabad for providing the required resources to conduct the current research work.

\section{References}

[1] A. Cummings, "Sound transmission through duct walls," Journal of Sound and Vibration, vol. 239, no. 4, pp. 731-765, 2001.

[2] W. H. Louisell, Coupled Mode and Parametric Electronics, John Wiley \& Sons, New York, NY, USA, 1960.

[3] I. L. Ver and L. L. Beranek, Noise and Vibration Control Engineering: Principles and Applications, John Wiley \& Sons, New York, NY, USA, 2006.

[4] B. Venkatesham, M. Tiwari, and M. L. Munjal, "Prediction of breakout noise from a rectangular duct with compliant walls," International Journal of Acoustics and Vibrations, vol. 16, no. 4, pp. 180-190, 2011.

[5] B. Venkatesham, M. Tiwari, and M. L. Munjal, "Analytical prediction of break-out noise from a reactive rectangular plenum with four flexible walls," The Journal of the Acoustical Society of America, vol. 128, no. 4, pp. 1789-1799, 2010.
[6] C. E. Wallace, "Radiation resistance of a rectangular panel," Journal of the Acoustical Society of America, vol. 51, no. 3, pp. 946-952, 1972.

[7] T. Ran Lin and J. Pan, "Sound radiation characteristics of a boxtype structure," Journal of Sound and Vibration, vol. 325, no. 4-5, pp. 835-851, 2009.

[8] S. M. Kim and M. J. Brennan, "A compact matrix formulation using the impedance and mobility approach for the analysis of structural-acoustic systems," Journal of Sound and Vibration, vol. 223, no. 1, pp. 97-113, 1999.

[9] H. P. Lee, "Natural frequencies and modes of cylindrical polygonal ducts," Journal of Sound and Vibration, vol. 164, no. 1, pp. 182-187, 1993.

[10] ANSYS Inc, ANSYS 13, User guide, 2013.

[11] LMS International, LMS Virtual Lab Rev 13, User's Manual, 2013. 


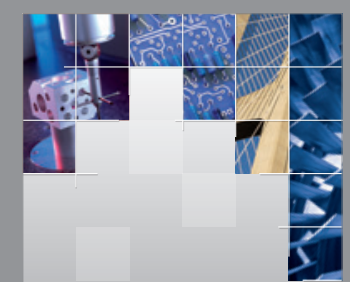

\section{Enfincering}
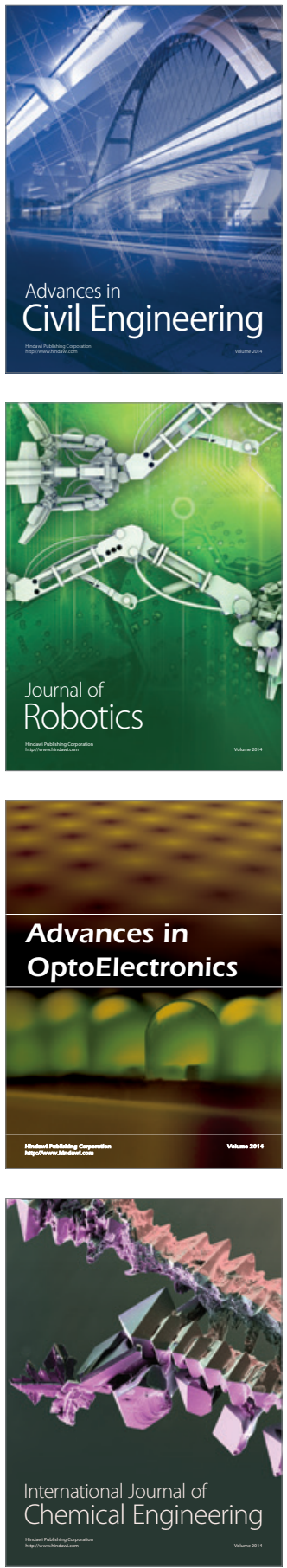

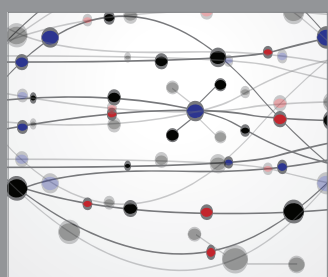

The Scientific World Journal

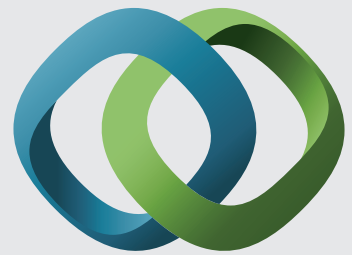

\section{Hindawi}

Submit your manuscripts at

http://www.hindawi.com
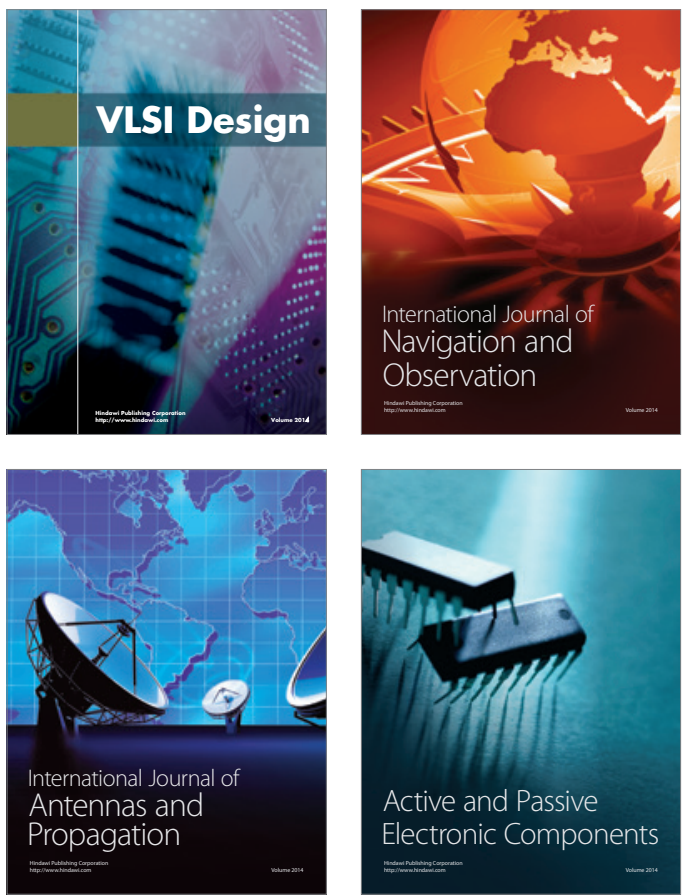
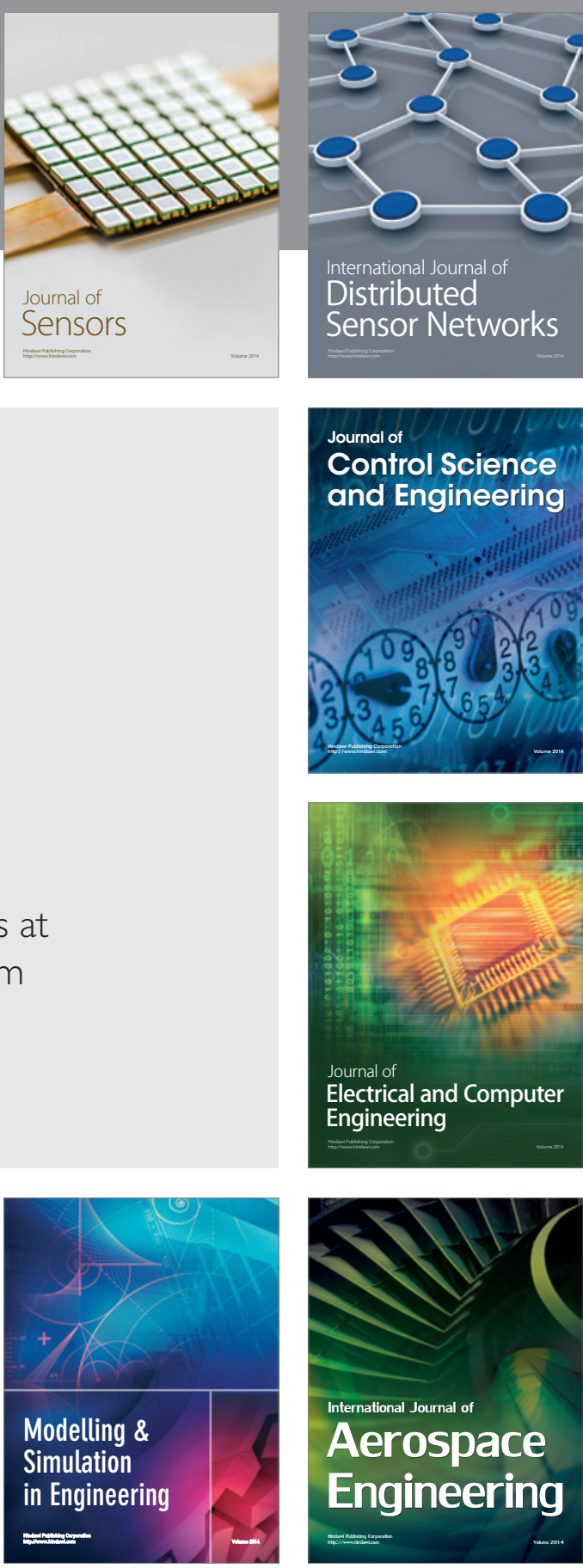

International Journal of

Distributed

Sensor Networks

Journal of

Control Science

and Engineering
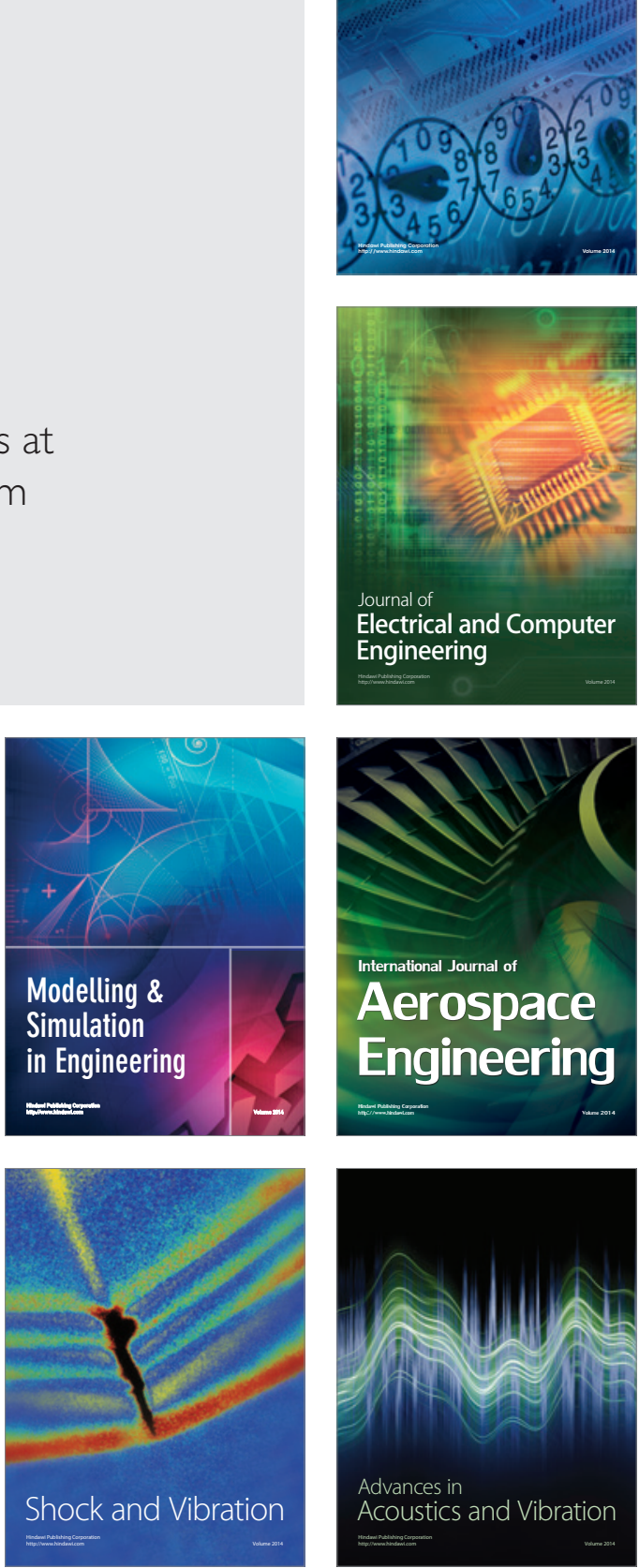